\title{
Experimental and computational electrochemistry of quinazolinespirohexadienone molecular switches - differential electrochromic vs photochromic behavior
}

\author{
Eric W. Webb, Jonathan P. Moerdyk, Kyndra B. Sluiter, Benjamin J. Pollock, \\ Amy L. Speelman, Eugene J. Lynch, William F. Polik and Jason G. Gillmore
}

\author{
Full Research Paper \\ Address: \\ Department of Chemistry, Hope College, 35 East 12th Street, \\ Holland, MI 49422-9000, USA \\ Email: \\ Jason G. Gillmore* - gillmore@hope.edu \\ ${ }^{*}$ Corresponding author \\ Keywords: \\ cyclic voltammetry; density functional theory; heterocycles; molecular \\ switches; photochromic photooxidants; spirocycles

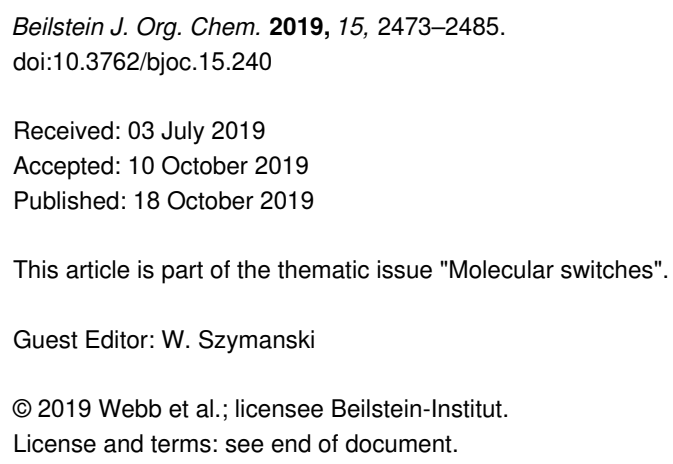

\begin{abstract}
Our undergraduate research group has long focused on the preparation and investigation of electron-deficient analogs of the perimidinespirohexadienone (PSHD) family of photochromic molecular switches for potential application as "photochromic photooxidants" for gating sensitivity to photoinduced charge transfer. We previously reported the photochemistry of two closely related and more reducible quinazolinespirohexadienones (QSHDs), wherein the naphthalene of the PSHD is replaced with a quinoline. In the present work, we report our investigation of the electrochemistry of these asymmetric QSHDs. In addition to the short wavelength and photochromic long-wavelength isomers, we have found that a second, distinct long-wavelength isomer is produced electrochemically. This different long-wavelength isomer arises from a difference in the regiochemistry of spirocyclic ring-opening. The structures of both long-wavelength isomers were ascertained by cyclic voltammetry and ${ }^{1} \mathrm{H}$ NMR analyses, in concert with computational modeling. These results are compared to those for the symmetric parent PSHD, which due to symmetry possesses only a single possible regioisomer upon either electrochemical or photochemical ring-opening. Density functional theory calculations of bond lengths, bond orders, and molecular orbitals allow the rationalization of this differential photochromic vs electrochromic behavior of the QSHDs.
\end{abstract}

\section{Introduction}

Photochromic molecular switches, in which light initiates reversible coloration of a short-wavelength isomer (SW) to a long-wavelength isomer (LW), which fades back to SW either thermally or photochemically, have become ubiquitous in a wide range of applications [1-5]. Typically, organic photochromism results from a spirocyclic ring-opening or other isomeri- 
zation which results in increased conjugation. Electrochromism is also of increasing materials relevance, e.g., for self-dimming automotive mirror and aircraft window darkening applications [6-8]. In electrochromic applications, the color change is generally due to a change in the oxidation state of a conjugated system. This change in the oxidation state is most often concomitant with conformational and orbital occupancy changes, rather than any $\sigma$-bond-forming or breaking processes. The viologens are perhaps the most ubiquitous example of small molecule organic electrochromism $[6,7,9]$.

One example that combines photochromic and electrochromic behavior (the latter of an unusual sort) is the class of perimidinespirohexadienones 1 (PSHDs) whose synthesis, electrochemistry and UV-vis spectroscopy were reported by Minkin and co-workers [10] for 1a (Scheme 1). Electrochemically, they report observing a single, two-electron reduction peak and two distinct one-electron oxidation peaks upon scanning using cyclic voltammetry. They therefore proposed [10] that the electrolysis of 1a proceeds by an "ECE" (electrochemical-chemicalelectrochemical) mechanism $\left(\mathbf{1 a} \rightarrow \mathbf{1 a}^{\cdot-} \rightarrow \mathbf{2 \mathbf { a } ^ { 0 - }} \rightarrow \mathbf{2 a}^{\mathbf{2}} \rightarrow\right.$ $\left.\mathbf{2} \mathbf{a}^{\cdot-} \rightarrow \mathbf{2 a}\right)$ in which the dienone portion of the molecule accepted the first electron, followed by a radical anion rearrangement to the long-wavelength isomer, whose radical anion is so much easier to reduce that it immediately accepts a second electron at this potential; on the oxidative return wave the subsequent oxidations of the LW dianion to its radical anion and then its neutral state are observed. Thus, in this unusual system, electrochromism proceeds by the same sort of spirocyclic ring-opening as the photochromic rearrangement but occurs from the radical anion rather than a photoexcited state. The reduction of the molecular switch necessary for electrochromism is in a sense catalytic: the rearranged product is reoxidized to a neutral LW isomer, which reverts thermally to SW upon standing, just as it does when the LW is generated photochemically.<smiles>[R]N1c2cccc3cccc(c23)NC12C=C(C(C)(C)C)C(=O)C(C(C)(C)C)=C2</smiles>
$1 a, b$

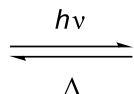

$\Delta$

a: $R=M e$

b: $\mathrm{R}=\mathrm{H}$<smiles>[R]Nc1cccc2cccc(N=C3C=C(C(C)(C)C)C(=O)C(C(C)(C)C)=C3)c12</smiles>

$2 a, b$
Scheme 1: PSHD photochromism [10]

The PSHD system was of interest to us as a potential photochromic photooxidant that would add an additional level of gating to photoinduced charge transfer (PICT) initiated processes (Figure 1). PSHDs were promising for this, as their photochromic reversion of LW back to SW proceeds purely thermally, leaving the long-wavelength absorption available for bimolecular PICT. Moreover, the LW is sufficiently more reducible that, even accounting for its lower excitation energy, the LW excited state, $\mathrm{LW}^{*}$, is more reducible than $\mathrm{SW}^{*}$, making LW the more potent photooxidant of the two. However, for practical use as photooxidants, the difference in the reduction potential between LW and SW would need to be increased further, and LW would need to be more reducible to be of use in photooxidation of relevant substrates (e.g., Dewar benzenes, quadricyclanes, or bishomocubanes as quantum amplified isomerization substrates [11-15], or vinylcarbazole or alkoxystyrene derivatives for radical cation cylcloaddition and polymerization reactions [16-20]). We thus proposed the replacement of the naphthalene in 1a with a more electron-deficient quinoline ring. Due to the saturated spirocyclic carbon insulating the dienone electrophore from the quinoline moiety in the SW form, we expected minimal change in the SW reduction potential relative to the PSHDs, but a significant difference for the completely conjugated LW isomer(s). Previously we reported the detailed synthesis of two novel quinazolinespirohexadienone (QSHD) photochromes 3a,b (Scheme 2) and their photochemical properties as well as a proof of structure for the photochemically generated long-wavelength isomer (pLW) 4a,b (not 5a,b) [21]. Herein, we report the electrochemistry of these QSHDs.

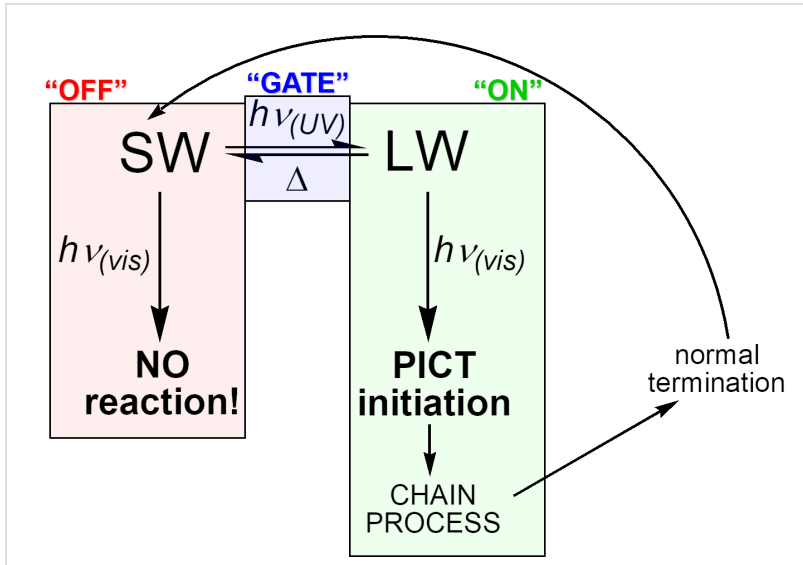

Figure 1: Proposed gating of sensitivity to photoinduced charge transfer by a photochromic photooxidant in which only LW is a competent photooxidant of the donor of interest.

\section{Results and Discussion Electrochemical analysis}

When we replicated cyclic voltammetry (CV) experiments on PSHDs, we observed similar voltammograms for both 1a and 1b (Figure 2), consistent with the two-electron reduction and two one-electron oxidation processes reported by Minkin for 1a 
<smiles>[R]c1cc(C)c2nccc3c2c1NC1(C=C([14CH2])C(=O)C(C(C)(C)C)=C1)C3</smiles>

3a,b

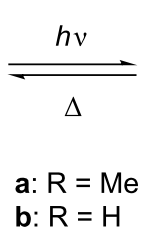

b: $\mathrm{R}=\mathrm{H}$<smiles>[R]c1cc(C)c2nccc(N=C3C=C(C(C)(C)C)C(=O)C(C(C)(C)C)=C3)c2c1N</smiles>

4a,b
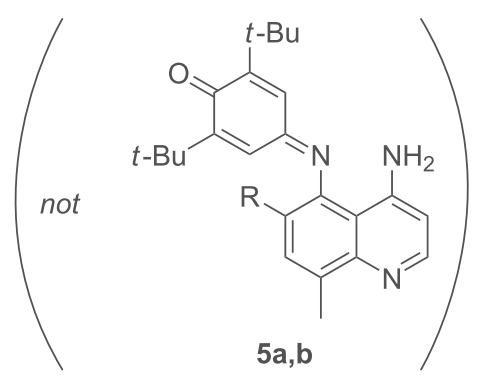

Scheme 2: QSHD photochromism [21].

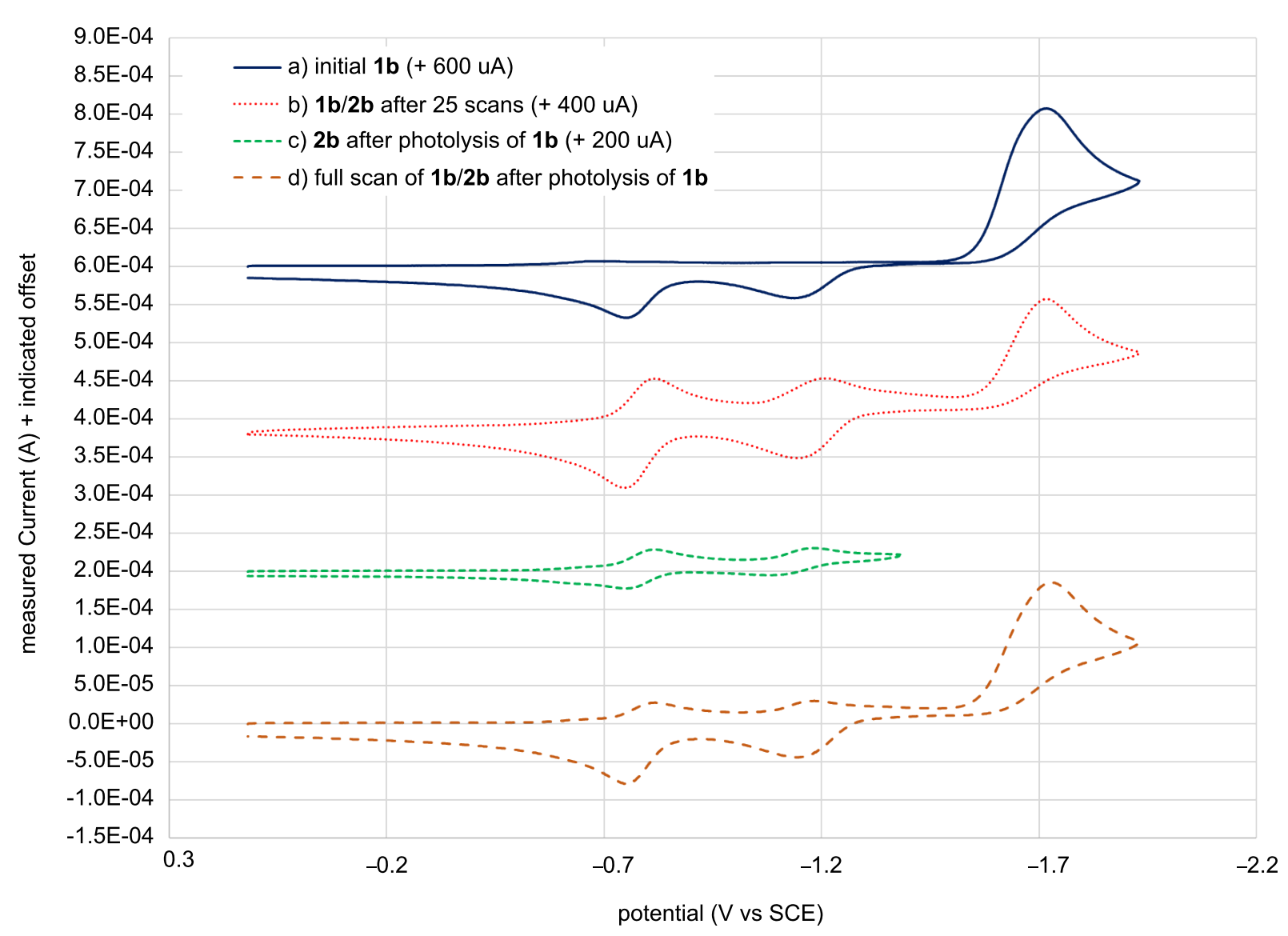

Figure 2: Cyclic voltammograms of a) $\mathbf{1 b}$ before irradiation or electrolysis (solid blue), b) $\mathbf{1 b} / \mathbf{2 b}$ after 25 scans (dotted red), c) $\mathbf{1 b} / \mathbf{2 b}$ upon photolysis of $\mathbf{1 b}$ (dashed green) scanned over a narrower potential window so as not to reduce $\mathbf{1} \mathbf{b}$, and d) $\mathbf{1} \mathbf{b} / \mathbf{2} \mathbf{b}$ scanning the full potential window after photolysis of $\mathbf{1 b}$ (dashed orange).

[10]. As expected, a growth of two reversible one-electron reduction-oxidation peaks was observed upon multiple scans, representing the reduction and oxidation of the electrogenerated long-wavelength form $\mathbf{1 b}$ generated in situ. As expected, either photolysis or multiple CV scans led to the same LW reduction and oxidation peaks (within the error bars indicated in Table 1). We also report an identical $E_{\text {red }}^{\mathrm{o}}$ of 2a as Minkin [10], though a $140 \mathrm{mV}$ difference was found in the $E^{\mathrm{o}}$ red of $\mathbf{1 a}$, which can be attributed at least in part to our use of half-peak potentials for all irreversible peaks, while Minkin reported peak potentials (our peak potentials were within $60 \mathrm{mV}$ of Minkin's value). We found the parent compound $\mathbf{1 b}$, whose electrochemistry was not previously reported by Minkin, to be $50 \mathrm{mV}$ less reducible than $1 \mathrm{a}(-1.68 \mathrm{~V}$ vs $-1.63 \mathrm{~V}$ for $1 \mathrm{a})$, in qualitative agreement with our computational predictions [22]. Similarly, 2b differed from $\mathbf{2 a}$ by only $20 \mathrm{mV}$ (Table 1 ) where computa- 
Table 1: Experimental and computational $E^{\circ}$ red of $\mathbf{1} \mathbf{a}, \mathbf{b}$ and $\mathbf{3 a}, \mathbf{b}$ and their $L W$ isomers, reported in $V$ vs SCE.

\begin{tabular}{|c|c|c|c|c|c|c|}
\hline \multirow[b]{2}{*}{ Compd. } & \multirow[b]{2}{*}{ Type } & \multicolumn{3}{|c|}{ Electrochemical } & \multicolumn{2}{|c|}{ Photochemical } \\
\hline & & $E^{\mathrm{o}}{ }_{\text {red }}(\mathrm{SW})^{\mathrm{a}}$ & $E^{\circ}{ }_{\text {red }}\left(\mathrm{eLW}^{--}\right)$ & $E_{\text {red }}^{\circ}(\mathrm{eLW})$ & $E_{\text {red }}^{\circ}\left(p L W^{-}\right)$ & $E_{\text {red }}^{\circ}(\mathrm{pLW})$ \\
\hline \multirow[t]{3}{*}{$1 a$} & literature ${ }^{b}$ & -1.77 & -1.325 & -0.85 & & \\
\hline & exptl.c & $-1.628 \pm 0.031$ & $-1.220 \pm 0.049$ & $-0.857 \pm 0.010$ & & \\
\hline & predicted $^{d}$ & -1.56 & & -0.89 & & -0.89 \\
\hline \multirow[t]{2}{*}{$1 b$} & expt|c & $-1.681 \pm 0.013$ & $-1.202 \pm 0.032$ & $-0.871 \pm 0.013$ & $-1.170 \pm 0.060$ & $-0.865 \pm 0.005$ \\
\hline & predicted $^{\mathrm{d}}$ & -1.70 & & -0.90 & & -0.90 \\
\hline \multirow[t]{2}{*}{$3 \mathbf{a}$} & $\operatorname{exptl^{C}}$ & $-1.632 \pm 0.030$ & $-1.26 \pm 0.11$ & $-0.866 \pm 0.009$ & $-1.029 \pm 0.035$ & $-0.730 \pm 0.005$ \\
\hline & predicted $^{d}$ & -1.61 & & -0.88 & & -0.72 \\
\hline \multirow[t]{2}{*}{$3 b$} & $\operatorname{exptl^{C}}$ & $-1.631 \pm 0.017$ & $\begin{array}{l}-1.069^{\mathrm{ad}} \pm \\
0.029\end{array}$ & $-0.843 \pm 0.012$ & $-1.008 \pm 0.024$ & $-0.729 \pm 0.004$ \\
\hline & predicted $^{\mathrm{d}}$ & -1.63 & & -0.86 & & -0.72 \\
\hline
\end{tabular}

alreversible peak. $E^{o}$ red is reported as the half-peak potential $E^{p / 2}$ red (except in literature value for 1a). beference [10]. Irreversible SW peak reported as peak potential ( $E^{\mathrm{p}}$ red $)$, not half-peak potential $\left(E^{\mathrm{p} / 2}\right.$ red $)$. ${ }^{\mathrm{C}}$ Experimental values in $\mathrm{CH}_{3} \mathrm{CN}$ containing $0.1 \mathrm{M} \mathrm{Bu} \mathrm{NPF}_{6}$, standardized vs ferrocene/ferrocenium and corrected to vs SCE as in reference [23]; error bars = one standard deviation from the mean of at least 7 replicates.

${ }^{\mathrm{d}}$ Computational $E_{\text {red }}^{\mathrm{o}}$ predicted using correlation 6 in reference [22] based on the energies of the corresponding ground-state and one-electronreduced species computed using B3LYP/6-31G(d) with implicit acetonitrile solvent using the CPCM solvent model with UAKS radii, on geometries optimized in the gas-phase; predictions of second reduction potentials are not possible by this method.

tions predicted a minimal difference. The electrogeneration of 2b through repeated potential step bulk electrolysis of $\mathbf{1 b}$ in acetonitrile- $d_{3}$ yielded a sufficient quantity of LW to obtain a ${ }^{1} \mathrm{H}$ NMR spectrum, which revealed identical chemical shifts as those for the photogenerated $\mathbf{2 b}$. First and second reduction potentials were also the same, within error limits, for photogenerated and electrogenerated $\mathbf{2 b}$, as would be expected. This is consistent with the excellent overlap of all four voltammograms in Figure 2.

The ECE mechanism reported by Minkin for the electrochromism was further supported by bulk electrochemical experiments. With repetitive conditioning and scanning under argon-deaerated conditions, the initially yellow 1b solution turned to an orange-red color, which we hypothesized to be the LW dianion, $\mathbf{2} \mathbf{b}^{\mathbf{2}-}$. Upon exposure to air this solution immediately turned green, the known color of the LW isomer $\mathbf{2 b}$. The addition of benzoquinone (a chemical oxidant) to the electrochemically reduced solution under argon gave similar results, consistent with our hypothesis. When the yellow solution remained open to the atmosphere during electrolysis, the initially yellow solution turned green at first (presumably while air oxidation of $\mathbf{2 b}^{\mathbf{2}-}$ to $\mathbf{2 b}$ could keep up with electrochemical reduction). With further electrolysis even these solutions turned to the orange-red color observed for the deaerated solutions. The solutions did become green upon prolonged exposure to air. This behavior seems indicative of insufficient transport of air into the cell through the small vents in the cell cap to replace the oxygen being consumed during repeated electrolytic scans. Similar results were observed for solutions of $\mathbf{3 b}$ suggesting a similar ECE mechanism to that of 1a is likely also occurring for 3b.

Cyclic voltammetric analysis of quinazolinespirohexadienone (QSHD) 3b (Figure 3) was qualitatively similar to the parent PSHDs 1a,b as expected based on structural similarity and computationally calculated molecular orbital diagrams (Figure 6 and Supporting Information File 1). Surprisingly, the $E^{\mathrm{o}}$ red of the electrochemically generated LW form of $\mathbf{3 a}$ was more negative by $10 \mathrm{mV}$ than that of $\mathbf{2 a}$, even with the more electron-deficient quinoline ring. Presumably this is because the 5-position on the benzene ring of the quinoline, is the least withdrawing point of attachment, and the inductive withdrawing properties of the quinoline nitrogen are far enough removed from the electrophore to not cause any appreciable change in reduction potential. The other qualitative difference for $\mathbf{3 b}$ was the presence of two LW reduction peaks (LW $\rightarrow$ $\mathrm{LW}^{\bullet-} \rightarrow \mathrm{LW}^{2-}$ ) on the first scan (Figure 3a, dotted red). However, the observation of the two LW reduction peaks was consistent with UV-vis spectroscopy that indicated a significant amount of a LW isomer upon solvation, and repetitive electrochemical scans exhibited the anticipated growth of the LW reduction-oxidation peaks as more of the LW isomer was generated electrochemically (Figure 3b, solid blue).

Most surprisingly, when $\mathbf{3 b}$ was photolyzed to form $\mathbf{4 b}$ in solution under similar conditions to our previous report [21] and then analyzed electrochemically (Figure $3 \mathrm{c}$ and d, dashed green and orange), four reduction (and oxidation) peaks in the region of the LW isomer were observed. Two reduction-oxidation 


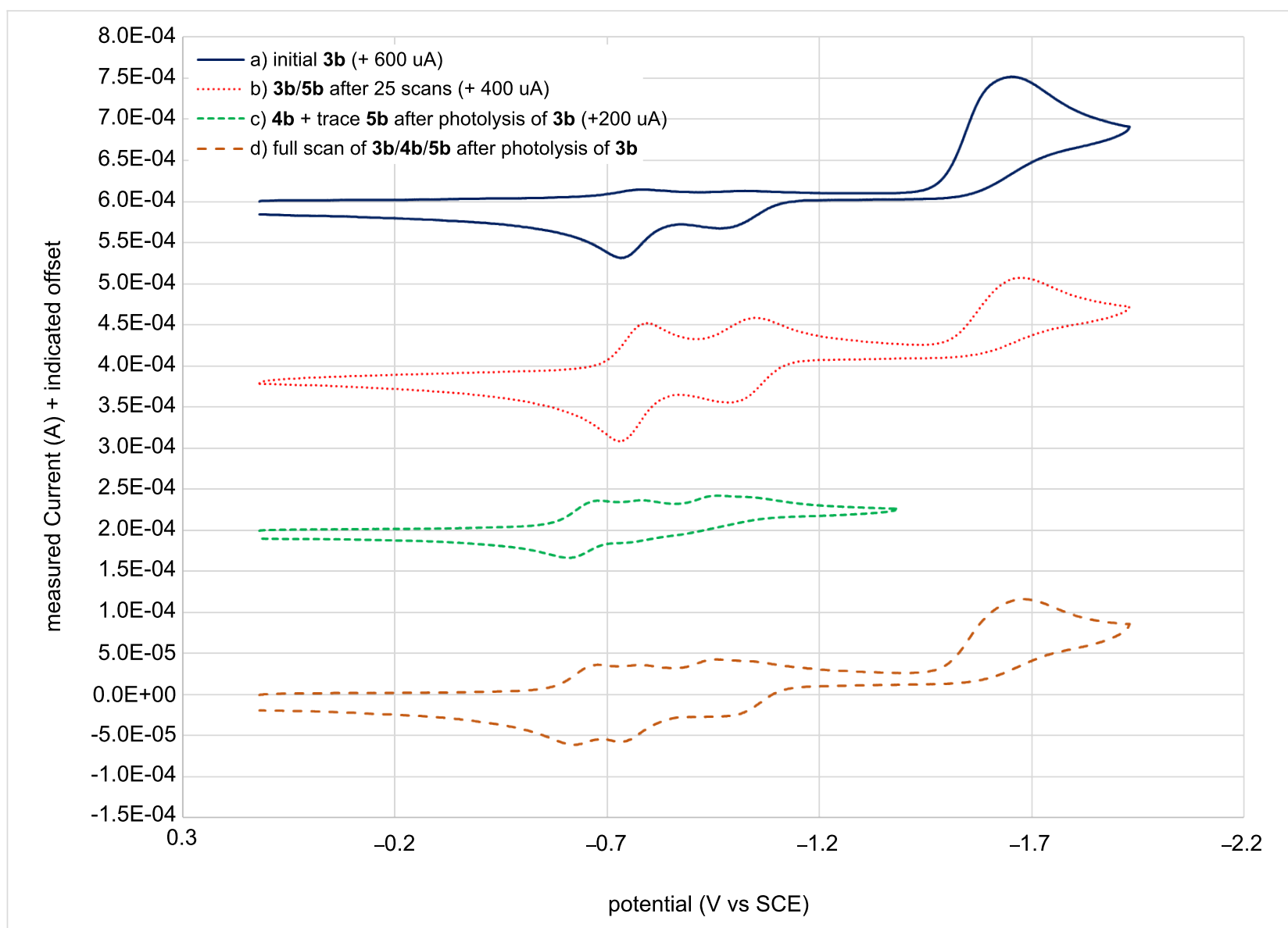

Figure 3: Cyclic voltammograms of a) $\mathbf{3 b}$ (with trace $\mathbf{5 b}$ ) before irradiation or electrolysis (solid blue), b) $\mathbf{3 b}+\mathbf{5 b}$ after 25 scans (dotted red) showing the growth of the two $\mathbf{5 b}$ reduction peaks, c) $\mathbf{3 b}$ (with trace $\mathbf{5 b}$ ) after photolyzing but without reducing $\mathbf{3 b}$ in the electrolysis (dashed green) which shows the two initial eLW $\mathbf{5 b}$ and two new pLW $\mathbf{4 b}$ reversible redox waves observed, and d) $\mathbf{3 b}+\mathbf{4} \mathbf{b}+\mathbf{5} \mathbf{b}$ observed by scanning the full potential window after the photolysis of $\mathbf{3 b}$ (dashed orange).

couples matched the potential of the electrogenerated LW form observed earlier while the other two peaks were shifted more positive by $60-110 \mathrm{mV}$ indicating the presence of a third electroactive species in addition to $\mathbf{3 b}$ and photogenerated $\mathbf{4 b}$. Given the asymmetric nature of $\mathbf{3 b}$, two distinct options for spirocyclic ring-opening exist, leading to $\mathbf{4 b}$ or $\mathbf{5 b}$. Thus, we postulated that the electrogenerated LW form was in fact $\mathbf{5 b}$.

Having found two distinct LW forms depending on generation by photolysis or electrolysis of SW $\mathbf{3 b}$, we turned our attention to whether a similar phenomenon was observed for 3a. Indeed, different redox peaks were observed in the same general LW region for the $\mathrm{CV}$ of photolyzed versus electrogenerated $\mathrm{LW}$ forms of 3a, consistent with the electrogenerated formation of 5a compared against the known formation of $\mathbf{4 a}$ via photolysis. The voltammograms of 3a (Figure 4) did however differ from both $\mathbf{3 b}$ and $\mathbf{1 b}$. A (presumably two-electron) reduction peak was observed for 3a but only one return oxidation wave was observed. Upon repeated scanning the two one-electron reductions of $\mathbf{5 a} \rightarrow \mathbf{5} \mathbf{a}^{\cdot-} \rightarrow \mathbf{5} \mathbf{a}^{2-}$ were observed, but still only a single (likely two-electron) return oxidation peak was observed, possibly indicating a large overpotential for the oxidation of $\mathbf{5} \mathbf{a}^{\mathbf{2}}$. It is possible that $\mathbf{3 a}$ undergoes only a one-electron reduction and rearrangement of $\mathbf{3 a} \rightarrow \mathbf{3 a}^{\mathbf{0}^{-}} \rightarrow \mathbf{5} \mathbf{a}^{\mathbf{0}}$ (without further reduction to $\mathbf{5 \mathbf { a } ^ { \mathbf { 2 } }}$ ) and subsequently only one oxidation to $\mathbf{5 a}$. But this would make the second one-electron reduction (thought to be $\mathbf{5} \mathbf{a}^{\mathbf{-}} \rightarrow \mathbf{5 a}^{\mathbf{2}}$ ) observed on repeated cycling unexplainable. A more likely explanation is that the two-electron ECE reduction of $\mathbf{3 a}$ still occurs to give $\mathbf{5} \mathbf{a}^{\mathbf{2}}$ but that the slight electrondonating nature of the additional methyl group destabilizes $\mathbf{5 a}^{\cdot-}$ enough to require a substantial overpotential for reoxidation of $\mathbf{5 \mathbf { a } ^ { 2 - }}$ to $\mathbf{5 \mathbf { a } ^ { - - }}$, such that it occurs at the same potential as oxidation of $\mathbf{5} \mathbf{a}^{\bullet-}$ back to neutral 5a. This could occur either sequentially at the same potential or in a single two-electron process. The latter explanation seems qualitatively in better agreement with the observed voltammogram in Figure 4.

In terms of achieving more potent photooxidants through the exchange of the naphthalene ring of the PSHDs for the more electron-deficient quinoline in the QSHDs, we had expected the 


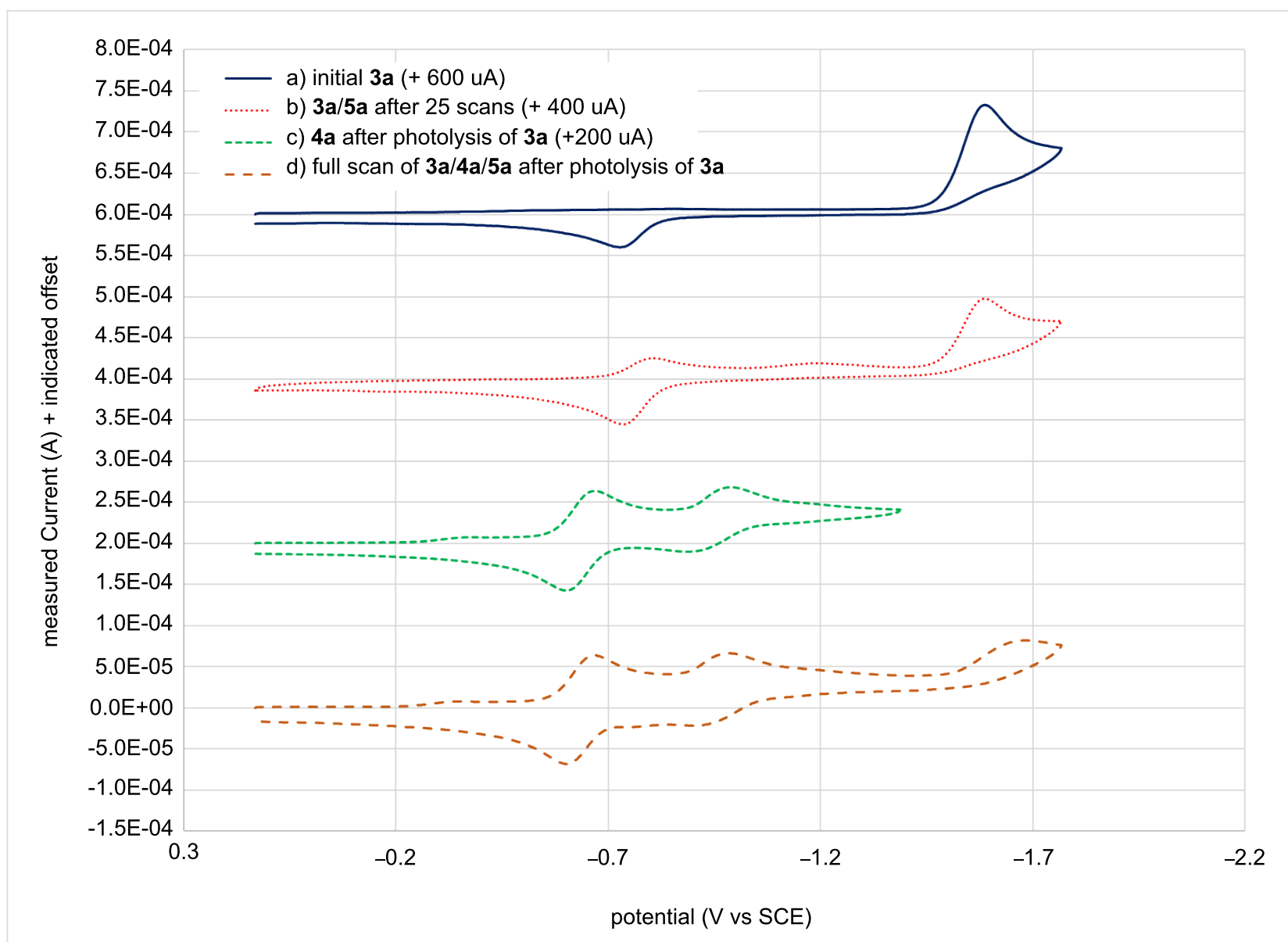

Figure 4: Cyclic voltammograms of a) $\mathbf{3} \mathbf{a}$ before irradiation or electrolysis (solid blue), b) $\mathbf{3} \mathbf{a}+\mathbf{5 a}$ after 25 scans (dotted red) showing the growth of the two eLW $5 \mathbf{a}$ reduction peaks, c) $\mathbf{3 a}$ after photolyzing but without reducing $\mathbf{3} \mathbf{a}$ in the electrolysis (dashed green) which shows the two different reversible redox waves observed for pLW $\mathbf{4 a}$, and d) $\mathbf{3 a}+\mathbf{4 a}+\mathbf{5 a}$ scanning the full potential window after the photolysis (dashed orange).

LW isomers to become more easily reducible, with minimal change in reduction potential for the SW isomers. Indeed $E^{\mathrm{o}}{ }_{\text {red }}$ of the SW isomers $\mathbf{1 b}, \mathbf{3 a}$, and $\mathbf{3 b}$ were the same within the error, and only $50 \mathrm{mV}$ more reducible than 1a. Comparing the $E^{\mathrm{o}}$ red of pLW isomers $(\mathbf{4 a}, \mathbf{b}$ relative to $\mathbf{2 a} \mathbf{a}, \mathbf{b})$, a roughly $140 \mathrm{mV}$ difference is observed, with $\mathbf{4}$ being more reducible than $\mathbf{2}$ as expected. However, the difference in reduction potential between PSHD and QSHD for eLW was much less. For $\mathbf{5 b} E^{\mathrm{o}}$ red was $28 \mathrm{mV}$ more positive than $\mathbf{2 b}$ indicating that $\mathbf{5} \mathbf{b}$ is a slightly better oxidant than the parent PSHD. But $E_{\text {red }}^{\mathrm{o}}$ of eLW 5a was surprisingly shifted $10 \mathrm{mV}$ more negative than PSHD LW 2a, meaning it was actually harder to oxidize. Ultimately $E^{\mathrm{o}}$ red of $\mathbf{2 a}, \mathbf{2 b}, \mathbf{5 a}$, and $\mathbf{5 b}$ are essentially the same within error limits. Apparently, the quinoline is not nearly as electron withdrawing when linked through the benzo ring as when it is linked through the heteroaromatic ring.

\section{Spectroscopic analysis}

The potential for two distinct products from electrolysis or photolysis as indicated through electrochemical analysis was further supported through NMR. Previous work [21] had conclusively shown through ${ }^{1} \mathrm{H}$ NOE NMR spectroscopy that the LW isomers resulting from photolysis of $\mathbf{3 a}$ and $\mathbf{3 b}$ were $\mathbf{4 a}$ and $\mathbf{4 b}$, which open toward the more electron-deficient heteroaromatic ring of the quinoline and away from the $\mathrm{R}$ group. Unfortunately, efforts to obtain a sufficient quantity of the electrogenerated LW form of $\mathbf{3 a}$ (i.e., $4 \mathbf{a}$ or $\mathbf{5 a}$ ) for definitive ${ }^{1} \mathrm{H}$ NMR spectra or NOE experiments were not successful However, both UV-vis and electrochemical measurements indicated small amounts of a long wavelength form present in the dark immediately upon solvation (i.e., a thermal or solvatochromic LW form), particularly in 3a. The presence of a LW isomer prior to irradiation or electrolysis was also consistent with the ${ }^{1} \mathrm{H}$ NMR spectrum of a sample of $\mathbf{3 a}$ which, while known to be pure in the solid state [21]), in solution showed the expected 3a chemical shifts but also smaller peaks (ca. $20 \%$ relative to 3a) with similar splitting and chemical shifts as those for photogenerated $\mathbf{4 a}$ (to which we initially erroneously attributed them [21]). However, the frequencies for this solvatochromic LW were slightly but distinctly different from either 
3a or photogenerated 4a (Figure 5a, e.g., consider protons $\mathbf{n}, \mathbf{g}$, and $\mathbf{v}$ ). Signals for $\mathbf{4 a}$ began to grow in with even very brief photolysis (Figure 5b), intentionally taken to low conversion (ca. 8\% relative to $3 \mathbf{a}$ ) to enable comparison to the solvatachromic LW (ca. 20\% relative to 3a). Moreover, as the oxidation and reduction peaks associated with eLW 5a (Figure 3b, dotted red) grow with increasing numbers of CV scans and match those present initially in solution in small amounts thermally (Figure 3a, solid blue), we conclude the electrogenerated and thermal LW forms are the same isomer $\mathbf{5 a}$, while it is the
$\mathrm{pLW}$ isomer 4a that grows in upon photolysis (Figure 3c, dashed green; Figure 5b). Furthermore, modest NOE enhancements can be observed even on the small amounts of 5a present in these solutions. These NOEs, while weak, did aid in assigning the peaks as labelled in Figure $5 \mathrm{~b}$ and demonstrate that the blue-labelled eLW peaks in Figure 5 are indeed on the same molecule, and that this is distinct from pLW $\mathbf{4 a}$ as studied previously by NOE [21]. Thus, NMR, while not conclusive on its own, was able to provide additional support for our structural assignment.

a) $3 b$ before photolysis (trace $5 b$ )

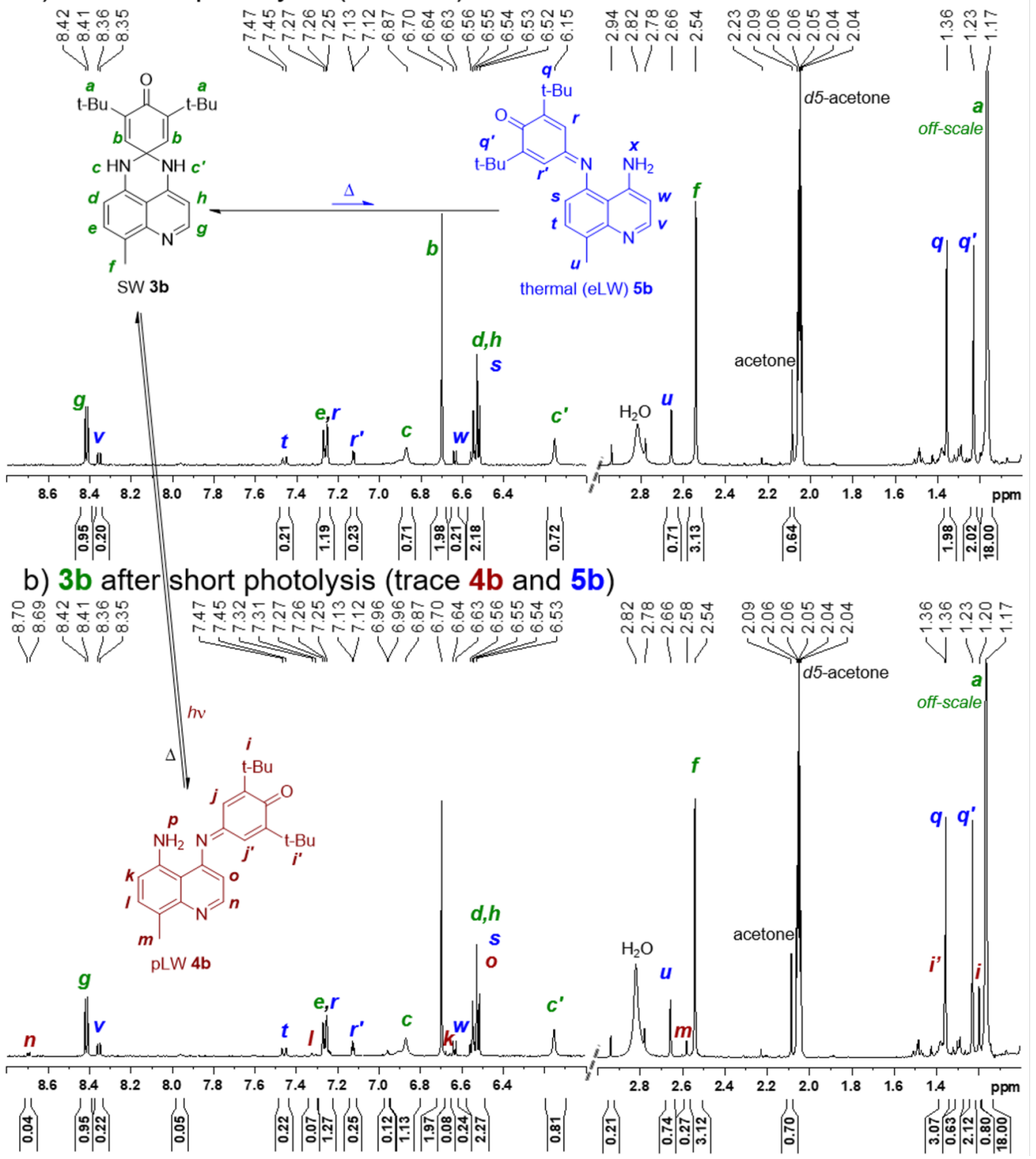

Figure 5: ${ }^{1} \mathrm{H}$ NMR distinction between SW 3a, thermal/eLW 5a, and pLW 4a, in acetone- $d_{6}$, as observed a) before and b) after photolysis. 
UV-vis spectra taken of eLW solutions generated by bulk electrolysis in acetonitrile and acetonitrile- $d_{3}$ were compared against photoirradiated ( $\mathrm{pLW}$ ) solutions. No difference was observed in the UV-vis spectrum of the LW isomer prepared from either photolysis or electrolysis of solutions of $\mathbf{1 b}$ (as expected due to symmetry). The $\lambda_{\max }$ for the $\mathbf{2} \mathbf{b}$ photogenerated solution was at $574 \mathrm{~nm}$ in acetonitrile and acetonitrile- $d_{3}$. The electrogenerated $\mathbf{2 b} \lambda_{\max }$ at $573 \mathrm{~nm}$ in both solvents differed by only $1 \mathbf{n m}$, within error limits of our instrumentation. For $\mathbf{4 a} / \mathbf{5} \mathbf{a}$ the $\lambda_{\max }$ in acetonitrile- $d_{3}$ was $539 \mathrm{~nm}$ for the photolyzed solution (4a) versus $529 \mathrm{~nm}$ for the electrolyzed (5a). Similarly, for $\mathbf{4 b}$ and $\mathbf{5 b}$, the photolyzed $\lambda_{\max }$ in acetonitrile was $558 \mathrm{~nm}$ versus $549 \mathrm{~nm}$ for the electrogenerated and was $564 \mathrm{~nm}$ versus the electrogenerated $550 \mathrm{~nm}$ in acetonitrile- $d_{3}$. The differences in the UV-vis spectrum of about $10 \mathrm{~nm}$ between eLW and pLW isomers of QSHDs 3 indicated a similar length for the conjugated system but a significant enough difference to indicate different species. This is consistent with the formation of two constitutional LW isomers that are structurally similar yet distinct, as the difference in absorbance would be expected to be noticeable but not large. Observation of no difference in the UV-vis spectrum of the LW isomer prepared from either photolysis or electrolysis of solutions of $\mathbf{1 b}$ (able to only form one LW isomer, $\mathbf{2 b}$ ) supports the formation of two different LW isomers for $\mathbf{3 a}, \mathbf{b}$ rather than attributing the small spectral changes to the presence of electrolyte in the electrolyzed solutions, to an interaction with air, or to a side reaction in solution. The shorter wavelength for electrogenerated $\mathbf{5 a}, \mathbf{b}$ may result from slightly less planarity and decreased conjugation versus the photogenerated $\mathbf{4 a}, \mathbf{b}$. The additional ortho-methyl group in 5b may exacerbate this sterically, and/or could contribute an inductively donating effect.

Finally, the thermal reversion of eLW 5a,b was visually and spectroscopically obvious to have begun within a few minutes, and to be complete within 12-18 hours. This is similar to what we previously reported for pLW 4a,b [21]. This comparatively slow and purely thermal reversion is consistent with the need for a thermodynamically unfavorable intramolecular (or solvent or adventitious acid/base-mediated) proton transfer to begin the reversion mechanism, as Minkin has described [10]. Interestingly, reversion of either LW species to SW is observed immediately upon removal of solvent, which played a role in complicating our analysis, as the LW species cannot be isolated as solids.

\section{Computational analysis}

As shown above, computationally predicted reduction potentials [7] were in very good agreement with those determined experimentally (Table 1). The mean absolute deviation between computational prediction and experimental measurement of
$E^{\mathrm{o}}{ }_{\text {red }}$ for all SW and LW structures in Table 1 is just $21 \mathrm{mV}$ (27 $\mathrm{mV}$ root mean squared deviation), not far from the $14 \mathrm{mV}$ mean standard deviation in the experimental measurements. This demonstrates that the computational correlation employed is useful in structural assignment and accurate within a standard of error of the experimental reduction potentials of these spirohexadienones' different constitutional SW and LW isomers.

Density functional theory (DFT) calculated molecular orbitals (MOs, e.g., Figure 6 and Supporting Information File 1) indicate that the LUMO (MO 106 for 3a) lies exclusively on the dienone moiety both in $\mathbf{1 b}$ and in the quinazolinespirohexadienone photochromes $\mathbf{3 a}, \mathbf{b}$. Thus, the dienone moiety is likely the electrophore in the SW in all PSHD and QSHD switches, just as Minkin [10] specifically asserted for 1a. These diagrams also suggested to us that QSHDs 3 might also undergo an ECE mechanism similar to PSHDs $\mathbf{1}$, as we have now confirmed experimentally.

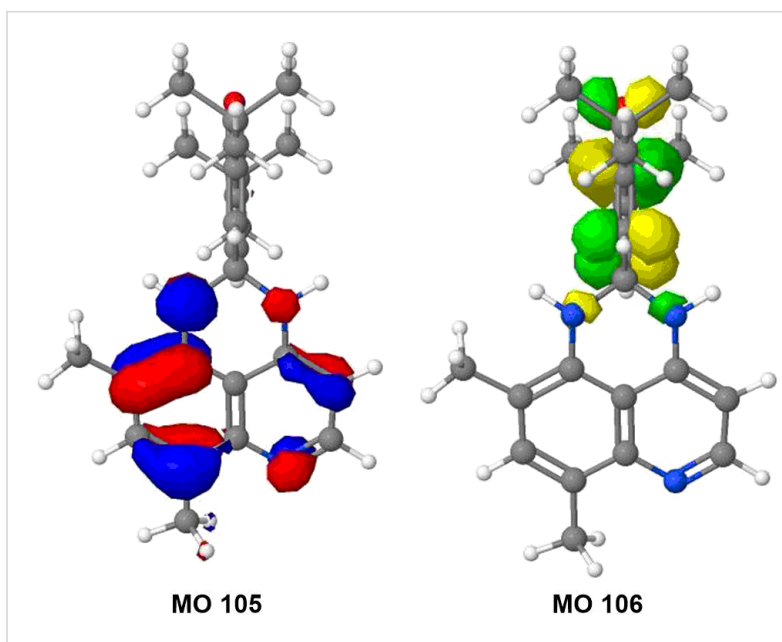

Figure 6: HOMO (MO 105, red and blue) and LUMO (MO 106, green and yellow) computed for $3 \mathbf{a}$ in its ground $\left(\mathrm{S}_{0}\right)$ state. Similar results were observed for the frontier orbitals of $\mathbf{1 b}$ and $\mathbf{3 b}$ (see Supporting Information File 1).

Having conclusively demonstrated the differential regiospecificity of photochromic vs electrochromic ring-opening of the QSHDs (Scheme 3) by experiment, we next sought to understand why SW would open differently upon excitation to SW* vs reduction to $\mathrm{SW}^{\bullet-}$. We turned to computation (of 3a, 4a, and 5a) for an explanation. Due to large differences in the methods for calculating excited and ground-states, the triplet $\mathrm{T}_{0}$ state was used instead of the singlet $S_{1}$ state as the photochemical intermediate $\left(\mathrm{SW}^{*}\right)$ for computational purposes. Since $\mathrm{T}_{0}$ is the lowest energy triplet state, it is amenable to a ground-state computation. While the real $\mathrm{SW}^{*}$ photochemical intermediate may likely be the first singlet excited state $\left(S_{1}\right), T_{0}$ and $S_{1}$ possess 


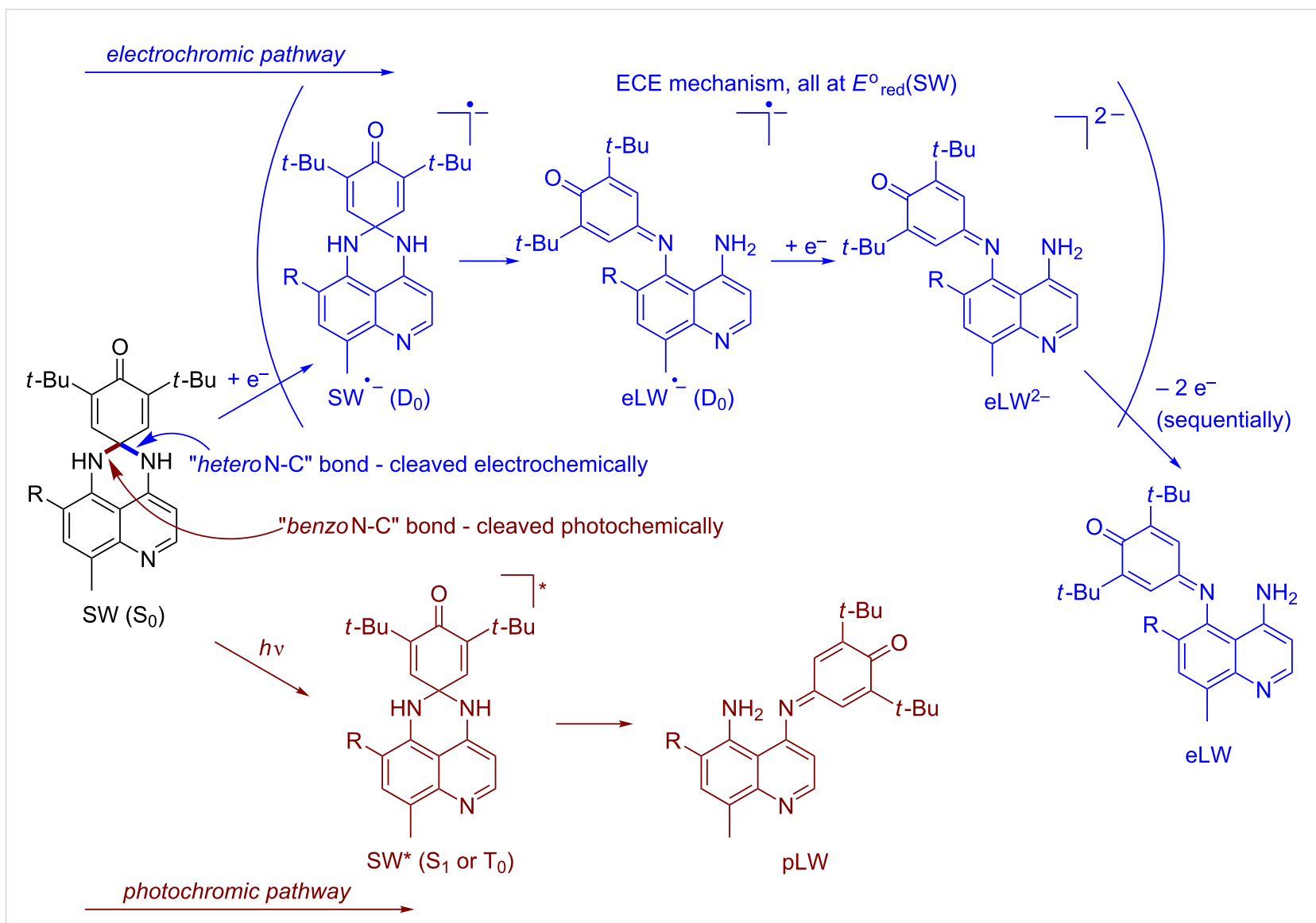

Scheme 3: Proposed mechanism for differential formation of pLW (4) and eLW (5) from SW (3).

equivalent orbital occupancy and differ only in their spin state. Our rationale for using $T_{0}$ rather than $S_{1}$ is that ignoring electron-exchange interaction introduces substantially less error than using different computational methods when comparing orbitals of $\mathrm{SW}^{*}$ to those of $\mathrm{SW}$ and $\mathrm{SW}^{\bullet-}$. Using $\mathrm{S}_{1}$ for $\mathrm{SW}^{*}$ would require unbalanced ground and excited-state calculations, e.g., time-independent and time-dependent density functional theories, or single-reference and multi-reference methods. However, using $\mathrm{T}_{0}$ for $\mathrm{SW}^{*}$ is a straightforward ground-state calculation, as are the calculations of $\mathrm{D}_{0}$ (the radical anion) and $\mathrm{S}_{0}$.

Clearly, as shown in Figure 7, the difference in reduction vs excitation is the occupancy in what was formerly the HOMO of $\mathrm{SW}$. Because $\mathrm{S}_{0}$ is the common precursor to both $\mathrm{T}_{0}$ and $\mathrm{D}_{0}$, analysis of the $S_{0}$ MOs was used to explain differences in the electron distributions that lead to two different products upon either excitation to form $\mathrm{SW}^{*}$ (yielding $\mathrm{pLW} 4$ ) or reduction to form $\mathrm{SW}^{\bullet-}$ (yielding eLW 5). This approach of using the $\mathrm{S}_{0}$ MOs was validated computationally, as we found there is little change in the character and relative energies of the MOs among $S_{0}, T_{0}$, and $D_{0}$. The calculated isosurface generated for the $S_{0}$ highest occupied molecular orbital (HOMO), MO 105, and lowest unoccupied molecular orbital (LUMO), MO 106, of 3a are displayed in Figure 6. MO 105 allows for a direct comparison of the $\mathrm{T}_{0}$ and $\mathrm{D}_{0}$ electron distributions, as these two states differ only in the population of this orbital. There is more contribution from this $\mathrm{MO}$ to the $\mathrm{N}-\mathrm{C}$ bond (hereafter designated the benzo $\mathrm{N}-\mathrm{C}$ bond, cf. Scheme 3) of the nitrogen on the benzo ring of the quinoline moiety than the $\mathrm{N}-\mathrm{C}$ bond of the nitrogen off the heterocyclic ring of the quinoline moiety (here-

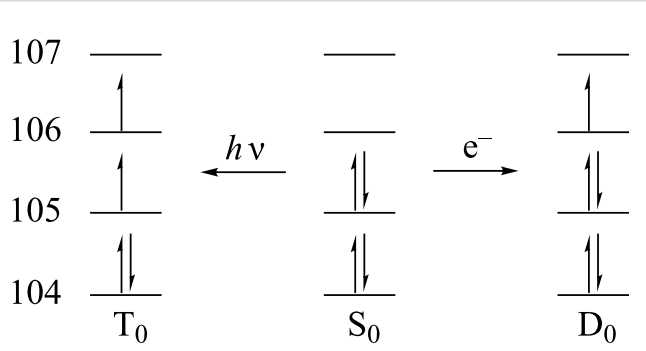

Figure 7: Frontier orbital occupancies of relevant electronic states of 3a. Note: the photochemical excited state may be $T_{0}$ (as pictured) or perhaps more likely $S_{1}$ (inverted spin in molecular orbital 106 relative to $T_{0}$ ), but $T_{0}$ is more computationally tractable and is equivalent to $S_{1}$ for orbital occupancy arguments. 
after referred to as the hetero $\mathrm{N}-\mathrm{C}$ bond, cf. Scheme 3). This asymmetrical MO contribution is consistent with experimental observations. The absence of an electron from this orbital 105 in the case of $\mathrm{T}_{0}$ results in the preferential weakening of the benzo $\mathrm{N}-\mathrm{C}$ bond over the hetero $\mathrm{N}-\mathrm{C}$ bond. The formation of pLW from $\mathrm{SW}\left(\mathrm{T}_{0}\right)$ results from the breaking of this weaker bond. More electron density in the benzoN-C bond in orbital 105 might possibly suggest a stronger bond when the orbital is fully filled (as in $\mathrm{D}_{0}$ ), and could suggest that the hetero $\mathrm{N}-\mathrm{C}$ bond might be the more likely to rupture upon reduction to $\mathrm{SW}^{\bullet-}$.

It is common to think of thermal ring-opening as looking more like that of the biradical $\left(\mathrm{T}_{0}\right.$ or $\left.\mathrm{S}_{1}\right)$ than of the radical anion $\left(D_{0}\right)$, so we might have presumed the structure of any thermal or solvatochromic LW isomer that occurred to have been that of pLW (4). However, the same rationalization that more electron density in the benzo $\mathrm{N}-\mathrm{C}$ bond in orbital 105 might possibly suggest a stronger bond relative to the hetero $\mathrm{N}-\mathrm{C}$ bond when the orbital is fully filled in $\mathrm{S}_{0}$ is how we rationalize our observation that it is eLW (5b) that occurs in the only case where we see a purely thermal or solvatochromic cleavage. In turn we can then rationalize on the basis of sterics $(\mathrm{R}=\mathrm{Me}$ vs $\mathrm{H})$ that it is logical that this thermal or solvatochromic rupture might only be observable in $\mathbf{3 b}(\mathrm{R}=\mathrm{H})$ but not $\mathbf{3 a}(\mathrm{R}=\mathrm{Me})$. This is in good agreement with our experimental observations.

Our rationalization based on molecular orbitals was confirmed by looking at both bond lengths and bond orders of the two relevant $\mathrm{N}-\mathrm{C}$ bonds in $\mathrm{SW}^{\bullet-}$ and $\mathrm{SW}^{*}$. Bond order calculations provide a more quantitative explanation for the experimental observation. Because bond stability correlates to bond order, it is expected that the $\mathrm{N}-\mathrm{C}$ bond which breaks upon forming the LW product would possess a smaller bond order. The $\mathrm{BO}$ calculations for intermediate states $\mathrm{T}_{0}$ and $\mathrm{D}_{0}$ indeed support this prediction. Table 2 summarizes the results of $\mathrm{BO}$ calculations for both bonds in these states. Since geometry plays a critical role in the stability of bonds, only $\mathrm{BO}$ calculations done from optimized geometries for each state are displayed. As shown in
Table 2, hetero $\mathrm{N}-\mathrm{C}$ has a greater bond order than benzo $\mathrm{N}-\mathrm{C}$ in $\mathrm{T}_{0}$, while the relative magnitude of these bond orders is reversed in $D_{0}$. This is consistent with the formation of eLW $5 \mathbf{a}$ from $3 \mathbf{a}^{\cdot-} \mathrm{D}_{0}$ (breaking the hetero $\mathrm{N}-\mathrm{C}$ bond) and $\mathrm{pLW} 4 \mathbf{4}$ from $\mathrm{SW}^{*} 3 \mathrm{a}^{*}$, modelled as $\mathrm{T}_{0}$ (breaking the benzo $\mathrm{N}-\mathrm{C}$ bond) as shown in the proposed mechanism in Scheme 3. Finally, bond lengths were derived from geometry optimizations for $\mathrm{D}_{0}$ and $\mathrm{T}_{0}$ with and without solvent and are also included in Table 2. There is an obvious inverse relationship between calculated bond orders and bond lengths. For $\mathrm{D}_{0}$, a longer bond length is observed for hetero $\mathrm{N}-\mathrm{C}$ while a longer bond length is observed for benzo $\mathrm{N}-\mathrm{C}$ in $\mathrm{T}_{0}$. These results, regardless of solvent or gasphase considerations, are consistent with the discussion above. In the cases of both $\mathrm{D}_{0}$ and $\mathrm{T}_{0}$, the longer bond is the one broken in the isomerization of SW 3a to eLW 5a and pLW 4a, respectively. Similar results are also observed for $\mathrm{S}_{0}$. Though the differences are much more modest in $\mathrm{S}_{0}$, the hetero $\mathrm{N}-\mathrm{C}$ bond is computed to be both longer and weaker, as in $\mathrm{D}_{0}$, and thus it makes sense that any thermal or solvatochromic LW is the eLW isomer.

\section{Conclusion}

While moving from PSHD (7) to QSHD (3) increased $\Delta E^{\mathrm{o}}$ red between SW and pLW isomers, and therefore capacity to gate photoinduced charge transfer, by about $130 \mathrm{mV}$, the excited state reduction potential $E^{*}$ red of pLW 4 remains $<+1.0 \mathrm{~V}$ vs SCE, insufficient to oxidize most donor molecules of relevance to materials applications. If our photochromic photooxidants are to be effective in real systems, the pLW will need to be made more electron deficient. Our computational predictions of the reduction potential [22], unfortunately not completed until after preparing the present system, were our first insight into the fact that electrochemical ring-opening was not yielding the structure we had previously proven for the photochromic $\mathrm{pLW}$. We have thus demonstrated these computation's practical utility in a real-world experimental situation, as well as their suitably high degree of accuracy. We are therefore hopeful they can help guide our search for practical photochromic photooxidants, with a more reducible $\mathrm{pLW}^{*}$.

\begin{tabular}{|c|c|c|c|c|}
\hline State & Bond & Bond order & Bond length $(\AA)$ & Consider for \\
\hline $\mathrm{S}_{0}$ & benzoN-C & 0.9425 & 1.478 & thermal LW/ \\
\hline $\mathrm{S}_{0}$ & hetero $\mathrm{N}-\mathrm{C}$ & 0.9346 & 1.478 & solvatochromism \\
\hline $\mathrm{D}_{0}$ & benzoN-C & 0.8879 & 1.508 & \multirow{2}{*}{ electrochromism } \\
\hline $\mathrm{D}_{0}$ & hetero $\mathrm{N}-\mathrm{C}$ & 0.8738 & 1.513 & \\
\hline $\mathrm{T}_{0}$ & benzoN-C & 0.8143 & 1.546 & \multirow{2}{*}{ photochromism } \\
\hline $\mathrm{T}_{0}$ & hetero $\mathrm{N}-\mathrm{C}$ & 0.8834 & 1.503 & \\
\hline
\end{tabular}


For now, our team of undergraduate researchers has conclusively demonstrated differential regiospecificity in the photochromic vs electrochromic spirocyclic ring-opening of these QSHD molecular switches to two different LW isomers. This may provide an interesting structural framework for molecular logic or other applications that complements the recently reviewed photoelectrochromic properties observed in a range of photochromic families upon the electrochemical oxidation of either their SW or pLW isomers [24]. We have also demonstrated that any modest amount of thermal (or solvatochromic) coloration of the QSHDs is due to small amounts of the electrochromic eLW isomer $\mathbf{5}$, rather than the photochromic $\mathrm{pLW}$ (4) as we had previously surmised [21]. Finally, we have been able to rationalize these results computationally on the basis of bond lengths, bond orders, and molecular orbital occupancy.

\section{Experimental Materials}

Acetonitrile was of the highest HPLC grade (used as received or dispensed through a nitrogen-purged MBraun MBS-SPS 07-299 solvent purification system) or highest anhydrous grade (used as received). Acetonitrile- $d_{3}$ and acetone- $d_{6}$ were used as received in $1 \mathrm{~g}$ ampules (Cambridge Isotope Labs). Ferrocene, tetrabutylammonioum hexafluorophosphate (TBAH), and silver nitrate were of electrochemical grade and used as received. Photochromes 1a,b were prepared according to the literature [10]. Photochromes 3a,b were prepared as we previously reported [21].

\section{Instrumentation}

Photochemical irradiations and UV-vis spectroscopy were performed as previously described [21] on $3 \mathrm{~mL}$ or $4 \mathrm{~mL}$ argonpurged acetonitrile solutions of 0.1 M TBAH supporting electrolyte and 1-5 mM analyte, sufficient to attain signals much greater than background over the full potential window considered.

Cyclic voltammetry was performed on a CHI Model 604a electrochemical analyzer or a BAS epsilon e2 electrochemical analyzer. (The equivalent BAS or CHI cells and electrodes could be used on either potentiostat interchangeably, with or without the BAS C3 cell stand.) Solutions were placed in a glass cell and bubbled with argon to deaerate for 3-5 minutes. Scans were taken under an argon blanket using a glassy carbon working electrode, a platinum wire counter electrode, and a separately sparged $\mathrm{Ag} / \mathrm{AgNO}_{3}(10 \mathrm{mM})$ nonaqueous reference electrode isolated from the working compartment with a Vycor frit. In some cases, a bare Ag wire was used as a pseudo-reference instead. The working, reference, and counter-electrodes were arranged in a triangle through a Teflon cell cap. Rather than relying on either the $\mathrm{Ag} / \mathrm{AgNO}_{3}$ reference or $\mathrm{Ag}$ wire pseudo-reference, the voltammetry was corrected to a ferrocene external reference. Ferrocene solutions were cyclically scanned before and after each analyte experiment, beginning in the positive (oxidative) direction over an $800 \mathrm{mV}$ window roughly centered on the reduction of $\mathrm{Fc} / \mathrm{Fc}^{+}$redox couple at a scan rate of $0.1-0.5 \mathrm{~V} / \mathrm{s}, 10^{-4}$ A sensitivity, and $1 \mathrm{mV}$ sample interval. Internal resistance (iR) compensation was manually set to 95-99.5\% of the measured resistance so that the peak separation for the reversible oxidation-reduction of ferrocene had a peak separation of ca. $60 \mathrm{mV}$ and good peak shape without entering oscillation. Typical iR compensation in acetonitrile ranged from 150-230 $\Omega$. Photochromic solutions were cyclically scanned beginning in the negative (reductive) direction at $0.1-0.5 \mathrm{~V} / \mathrm{s}$ with $1 \mathrm{mV}$ sample interval over an appropriate range of potentials and current sensitivity to observe the redox couples of either SW and LW or just LW isomers as desired, without reaching the solvent breakdown limit. Reduction potentials were taken as the half-peak potential of irreversible peaks or the midpoint of reversible peaks, standardized versus ferrocene (measured before and after each analyte sample), and corrected to versus SCE by adding $0.38 \mathrm{~V}$ [23]. At least seven replicates of each data point were obtained, with the mean value reported with error bars indicating the standard deviation from the mean among all replicates.

Potential step bulk electrolyses were performed on $3 \mathrm{~mL}$ argonpurged acetonitrile or acetonitrile- $d_{3}$ solutions of $2 \mathrm{mM}$ analyte and 0.1 M TBAH. The solution was placed in a glass cell prepared by cutting the top off a $7 \mathrm{~mL}$ scintillation vial and fireglazing the edges. The outer rubber of a 19/22 septum was removed with a razor blade and used to cap the vial. The rubber had holes drilled for a reference and auxiliary electrode and a slit cut for a $7 \times 70 \mathrm{~mm}$ platinum mesh working electrode so that the surface of the mesh faced the working and auxiliary electrodes. Teflon tubing was inserted through a pinhole in the septum for an argon purge and vent. The setup used a CHI112 nonaqueous $\mathrm{Ag} / \mathrm{AgNO}_{3}$ reference electrode. The auxiliary electrode was formed by removing the silver wire from a CHI112 nonaqueous reference electrode and replacing it with a rolled $7 \times 70 \mathrm{~mm}$ piece of platinum mesh. The tube was filled with supporting electrolyte. Electrolyses were run on 2 to $3 \mathrm{~mL}$ samples, placing the platinum mesh electrode ca. $20 \mathrm{~mm}$ into the solution. To avoid the buildup of charge while maximizing current and efficiency, solutions were set to precondition before scanning the potential window with multiple repetitions run. Solutions of $\mathbf{1 b}$ were preconditioned at $-2.5 \mathrm{~V}$ for 5 seconds and $0 \mathrm{~V}$ for 6 seconds and 16-20 repetitions run. Solutions of 3a,b were preconditioned at $-2.2 \mathrm{~V}$ for 5 seconds and $0 \mathrm{~V}$ for 6 seconds with 16 repetitions. The electrolyzed solutions were opened to air or had a chemical oxidant (benzoquinone) added to complete the reduction of the dianion to the LW isomer. 
NMR spectroscopy was performed on samples $5 \mathrm{~mm}$ NMR tubes (Wilmad) made of clear quartz (photolyzed samples) or amber pyrex (dark samples) on a Varian Mercury or Bruker AvanceIII $400 \mathrm{MHz}$ NMR. ${ }^{1} \mathrm{H}$ NMR experiments on 5a were performed on an argon-purged, ca. $24 \mathrm{mM}$ solution in acetone$d_{6}$. 1D NOE spectra were collected using 400 manually interleaved scans with a 4 s relaxation delay, targeting a single peak per experiment, in a manner similar to that previously reported [21] for photogenerated $\mathbf{4 a}, \mathbf{b}$.

\section{Computational modeling}

Predicted ground-state reduction potentials were computed based on the energy difference of the ground-state molecule $\left(\mathrm{S}_{0}\right)$ and its one electron-reduced $\left(\mathrm{D}_{0}\right)$ radical anion and our published correlation of this energy difference with experimental reduction potentials (vs SCE in acetonitrile) [22]. Gas-phase geometries were optimized at the B3LYP/6-31G(d) level of theory. Single point energies were computed at the same level of theory with implicit acetonitrile solvent implemented using the Conductor-like Polarizable Continuum Model with UAKS radii. These computations were performed using the Gaussian 03 software package [25], implemented through the WebMO [26] graphical user interface on the Curie cluster [27] in the Hope College Computational Science \& Modeling Laboratory on a single node (a single $2.60 \mathrm{GHz}$ AMD Opteron-252 processor with 8 GB RAM and 250 GB HD).

Calculations of bond length, bond order, and molecular orbitals to rationalize the observed differential photochromic and electrochromic ring-opening of $\mathbf{1}$ to $\mathbf{2}$ and $\mathbf{3}$, respectively, were performed on the Midwest Undergraduate Computation Chemistry Consortium (MU3C) cluster [28,29]. Computations were performed on a single node (dual Intel X5650 CPU, with 6 cores running at $2.66 \mathrm{GHz}$ ) using the Gaussian 09 [30] software package implemented through the WebMO [26] graphical user interface. Restricted open-shell Hartree-Fock (ROHF) theory [31] with the Becke 3, Lee, Yang, and Parr (B3LYP) hybrid functional [32-34] was used for geometry optimizations, molecular orbitals, and bond orders calculations with the 6-31G(d) basis set [35] for open-shell species $\left(\mathrm{T}_{0}\right.$ and $\left.\mathrm{D}_{0}\right)$, while conventional B3LYP (with standard Hartree-Fock theory) was used for closed-shell $\mathrm{S}_{0}$ calculations. The concerted use of ROHF and B3LYP provides a restricted open-shell B3LYP (DFT) method, which was particularly important to obtaining good bond orders for open-shell $\left(\mathrm{T}_{0}\right.$ and $\left.\mathrm{D}_{0}\right)$ species. Bond orders were calculated using the Natural Bond Order (NBO) 3.1 package [36] contained within Gaussian 09. The geometry was first optimized for the $S_{0}$ state in the gas phase. Based on this starting point, geometries for $S_{0}, T_{0}$, and the one-electron reduced $D_{0}$ states were then (re)optimized with an implemented acetonitrile conductor-like polarizable continuum model
(CPCM) as the self-consistent reaction field (SCRF) [37]. It is from these implicit solvent-optimized geometries that reported bond lengths were derived. Molecular orbital and bond order calculations were subsequently performed on these geometries.

\section{Supporting Information}

\author{
Supporting Information File 1 \\ Additional figures and Z-matrices. \\ [https://www.beilstein-journals.org/bjoc/content/ \\ supplementary/1860-5397-15-240-S1.pdf]
}

\section{Supporting Information File 2}

Complete data sets for experimental and computational reduction potentials of all compounds.

[https://www.beilstein-journals.org/bjoc/content/

supplementary/1860-5397-15-240-S2.xlsx]

\section{Acknowledgements}

This work was funded by a Camille \& Henry Dreyfus Foundation Start-up Award (SU-04-040), a Cottrell College Science Award from Research Corporation (CC6653), and a Faculty Early Career Development Grant (CHE-0952768) from the US National Science Foundation (NSF). This work was also funded in part by a grant to Hope College from the Howard Hughes Medical Institute through the Undergraduate Science Education Program, which provided support for the Curie cluster [27] in the Hope College Computational Science \& Modeling (CSM) Laboratory and to ALS (Computational Science \& Modeling Scholars Program) and JPM (HHMI Research Scholars Program). Additional computations were conducted on the MU3C [28,29] cluster, supported by Major Research Instrumentation grants (CHE-0520704 and CHE-1039925) from the NSF, also housed in the Hope College CSM Laboratory. Support from CSM Laboratory director Prof. Brent P. Krueger and former staff member Mr. Paul Van Allsburg is also gratefully acknowledged. ALS acknowledges additional support from a Jean Dreyfus Boissevain Scholarship awarded to the Hope College Chemistry Department by the Camille \& Henry Dreyfus Foundation. EJL (home institution College of the Canyons, Santa Clarita, CA) acknowledges support by a Research Experiences for Undergraduates Site award (CHE0851194) to the Hope College Chemistry Department from the NSF.

\section{ORCID ${ }^{\circledR}$ iDs}

William F. Polik - https://orcid.org/0000-0003-0419-5135 Jason G. Gillmore - https://orcid.org/0000-0001-7506-3645 


\section{References}

1. Crano, J. C.; Guglielmetti, R. J., Eds. Organic Photochromic and Thermochromic Compounds; Plenum Press: New York, NY, USA, 1999; Vol. 1. doi:10.1007/b114211

2. Duerr, H.; Bouas-Laurent, H., Eds. Photochromism: Molecules and Systems, revised ed.; Elsevier: Amsterdam, 2003.

3. Desvergne, J.-P.; Pozzo, J.-L., Eds. Proceedings of the fourth International Symposium on Photochromism Photoswitchable Molecular Systems and Devices. Mol. Cryst. Liq. Cryst. 2005, 430-431, 1-586. doi:10.1080/15421400590946073

4. Branda, N.; Tian, H., Eds. Organic Photoswitchable Multifunctional Molecules and Materials. Dyes Pigm. 2011, 89, 193-336. doi:10.1016/j.dyepig.2010.12.002

5. Favaro, G.; Irie, M., Eds. Special issue on Photochromism 1 and 2. J. Photochem. Photobiol., C 2011, 12, 71-236. doi:10.1016/j.jphotochemrev.2011.08.004

6. Monk, P. M. S.; Mortimer, R. J.; Rosseinsky, D. R. Electrochromism and Electrochromic Devices; Cambridge University Press: Cambridge, UK, 2007. doi:10.1017/cbo9780511550959 and references therein.

7. Baumann, K. L.; Lin, R.; Giri, P.; Franz, S. Protic-Soluble Organic Electrochromic Compounds. U.S. Pat. Appl. US2017/0146880 A1, May 25, 2017.

8. Jarosz, T.; Gebka, K.; Stolarczyk, A.; Domagala, W. Polymers (Basel, Switz.) 2019, 11, 273. doi:10.3390/polym11020273 and references therein.

9. Madasamy, K.; Velayutham, D.; Suryanarayanan, V.; Kathiresan, M.; Ho, K.-C. J. Mater. Chem. C 2019, 7, 4622-4637. doi:10.1039/c9tc00416e

10. Minkin, V. I.; Komissarov, V. N.; Kharlanov, V. A. Perimidinespirocyclohexadienones. In Organic Photochromic and Thermochromic Compounds; Crano, J. C.; Guglielmetti, R. J., Eds.; Plenum Press: New York, NY, USA, 1999; Vol. 1, pp 315-340. doi:10.1007/0-306-46911-1_9 and references therein.

11. Gillmore, J. G.; Neiser, J. D.; McManus, K. A.; Roh, Y.; Dombrowski, G. W.; Brown, T. G.; Dinnocenzo, J. P.; Farid, S.; Robello, D. R. Macromolecules 2005, 38, 7684-7694. doi:10.1021/ma050348k

12. Kavarnos, G. J.; Turro, N. J. Chem. Rev. 1986, 86, 401-449. doi:10.1021/cr00072a005 and references therein.

13. Borsub, N.; Kutal, C. J. Am. Chem. Soc. 1984, 106, 4826-4828. doi:10.1021/ja00329a030

14. Evans, T. R.; Wake, R. W.; Sifain, M. M. Tetrahedron Lett. 1973, 14, 701-704. doi:10.1016/s0040-4039(00)72438-5

15. Hasegawa, E.; Okada, K.; Ikeda, H.; Yamashita, Y.; Mukai, T. J. Org. Chem. 1991, 56, 2170-2178. doi:10.1021/jo00006a039

16. Bauld, N. L. Hole and electron transfer catalyzed pericyclic reactions. In Advances in Electron Transfer Chemistry; Mariano, P. S., Ed.; JAI Press: Greenwich, CT, 1992; pp 1-66. and references therein.

17. Bauld, N. L.; Gao, D.; Aplin, J. T. J. Phys. Org. Chem. 1999, 12, 808-818. doi:10.1002/(sici)1099-1395(199911)12:11<808::aid-poc207>3.0.co;2$\mathrm{m}$

18. Bauld, N. L.; Gao, D. Polym. Int. 2000, 49, 253-259. doi:10.1002/(sici)1097-0126(200003)49:3<253::aid-pi352>3.0.co;2-p

19. Bauld, N. L.; Roh, Y. Tetrahedron Lett. 2001, 42, 1437-1439. doi:10.1016/s0040-4039(00)02301-7
20. Roh, Y.; Gao, D.; Bauld, N. L. Adv. Synth. Catal. 2001, 343, 481-489. doi:10.1002/1615-4169(200107)343:5<481::aid-adsc481>3.0.co;2-s

21. Moerdyk, J. P.; Speelman, A. L.; Kuper, K. E., III; Heiberger, B. R.; Ter Louw, R. P.; Zeller, D. J.; Radler, A. J.; Gillmore, J. G. J. Photochem. Photobiol., A 2009, 205, 84-92. doi:10.1016/j.jphotochem.2009.04.011

22. Lynch, E. J.; Speelman, A. L.; Curry, B. A.; Murillo, C. S.; Gillmore, J. G. J. Org. Chem. 2012, 77, 6423-6430. doi:10.1021/jo300853k

23. Pavlishchuk, V. V.; Addison, A. W. Inorg. Chim. Acta 2000, 298, 97-102. doi:10.1016/s0020-1693(99)00407-7

24. Barachevsky, V. A.; Butenko, V. G. Russ. J. Gen. Chem. 2018, 88, 2747-2772. doi:10.1134/s1070363218120459

25. Gaussian 03, Revision D.01; Gaussian, Inc.: Wallingford, CT, 2004.

26. Schmidt, J. R.; Polik, W. F. WebMO Pro version 9.1, WebMO Enterprise versions 10.1, 12.1, 14.0; WebMO LLC: Holland, MI, 2014; available from http://www.webmo.net (accessed June 2019).

27. Curie Cluster. http://curie.chem.hope.edu/ (accessed June 30, 2019).

28. MU3C - Midwest Undergraduate Computational Chemistry Consortium. http://mu3c.chem.hope.edu/ (accessed June 30, 2019).

29. Kuwata, K. T.; Kohen, D.; Krueger, B. P.; Polik, W. F. Counc. Undergrad. Res. Quart. 2012, 32 (4), 9-14.

30. Gaussian 09, Revision A.1; Gaussian, Inc.: Wallingford, CT, 2009.

31. Roothaan, C. C. J. Rev. Mod. Phys. 1960, 32, 179-185. doi:10.1103/revmodphys.32.179

32. Becke, A. D. J. Chem. Phys. 1996, 104, 1040-1046. doi:10.1063/1.470829

33. Becke, A. D. Phys. Rev. A 1988, 38, 3098-3100. doi:10.1103/physreva.38.3098

34. Lee, C.; Yang, W.; Parr, R. G. Phys. Rev. B 1988, 37, 785-789. doi:10.1103/physrevb.37.785

35. Hariharan, P. C.; Pople, J. A. Theor. Chim. Acta 1973, 28, 213-222. doi:10.1007/bf00533485

36. Glendening, E. D.; Reed, A. E.; Carpenter, J. E.; Weinhold, F. NBO, Version 3.1.

37. Tomasi, J.; Mennucci, B.; Cammi, R. Chem. Rev. 2005, 105, 2999-3094. doi:10.1021/cr9904009

\section{License and Terms}

This is an Open Access article under the terms of the Creative Commons Attribution License (http://creativecommons.org/licenses/by/4.0). Please note that the reuse, redistribution and reproduction in particular requires that the authors and source are credited.

The license is subject to the Beilstein Journal of Organic Chemistry terms and conditions: (https://www.beilstein-journals.org/bjoc)

The definitive version of this article is the electronic one which can be found at: doi:10.3762/bjoc. 15.240 